\title{
The Implications of Taylorism, Contingency Theory, Behavioral Management Theory and Systems Theory on Organization Management in the Globalization Era: A Comparative and Critical Review
}

\author{
Tang Huihui \\ Human Resource Management Department of Business School, Wuchang University of Technology, \\ Wuhan, China, 430000
}

Keywords: Theory; management; globalization

\begin{abstract}
This paper reviews four typical and classical organization management theories, taylorism, contingency theory, behavioral management theory and systems theory and attempts to explore their theoretical and practical values on organizational management in the globalized era. By comparing and clarifying the contribution and drawbacks of these four theories, this paper connects the theories to the contemporary issues of global organization management and discovers that the four classic theories still have significant impacts in the globalization era. The theories have transformed to fit the changing business environment and have combined with the contemporary advanced management practices to promote the organizational development.
\end{abstract}

\section{Introduction}

The theories about organization management have experienced continuous development for many years. Four classical theories are scientific management theory (taylorism), contingency theory, behavioral management theory and systems theory. As the society changes, they play different roles in illustrating the contemporary management practices. Nowadays, the world becomes more globalised and develops increasingly fast. It is necessary to examine the functioning of these four theories in such background critically. This article briefly reviews the theories, show evidences of their impacts on the globalised world and clarify some limitations of each theory.

\section{Taylorism}

The scientific management theory (Taylorism), is one of the most typical theories of organization management. The theory dates back to 1911 when Frederick Winslow Taylor initiated this scientific management approach in his masterpiece The Principles of Scientific Management. Aiming at maximizing productivity, Taylor (1911) claimed that it is important to systematically explore the work and figure out the best approach to it. He then established four principles of the theory: the true science representing the best management, scientific selection of workers, scientific training and development of workers and friendly collaboration between managers and workers.

Taylorism, which is a precious legacy and continues to develop, still has a strong connection with the 21st century management. Firstly, the scientific management influences the postmodern management and is applied in the postmodern organizations (Kemp, 2013). Through the lens of postmodern analysis, the four principles of taylorism are proved to be applicable in the postmodern world. The true science principle is utilized in measuring knowledge production (Jones, 2003). The Total Quality Management (TQM) is regarded as the development of the scientific selections of workers in postmodern era (Daniel, 1995). Moreover, the scientific selections of workers hinge on the workers' flexibility to undertake different work rather than the ability to do one single task. The applicability of the principle of scientific education and development of workers is concerned with involvement of employees in decision-making. The principle developed to empower workers rather than manage workers through domination (Clegg, 1990). As for the forth principle, it exists in the managing teamwork in postmodern organizations. The principle is coherent with the consideration that tasks should be dependent on each other for accomplishment (Gibson, 2008). 
Secondly, taylorism experiences transformation to respond the changes in the globalised world. A compelling evidence of this is the transformation from the mechanism taylorism to the digital taylorism on the knowledge competence in the organizations (Brown et al., 2010). In the 20th century, the knowledge of workers was acquired, identified and reorganized in the assembly line by management, while in the 21st century taylorism on knowledge is concerned with exploring knowledge work and codifying the working knowledge from the work into software and packages which can be transferred and operated by others worldwide. In this way, skills are taylorised and transmitted for reducing the cost of knowledge work across the world where there are well-educated labors. In practices, digital taylorism benefits many enterprises in different sectors, especially service sector.

However, there are critiques of the implications of taylorism for the current management. The 'one-best-way' of management in taylorism is not really objective (Wren, 1994). Scholars argued that scientific theory is only suitable in the modern times. The reason is that postmodern thinking of organizations emphasizes on a transient and ephemeral reality whereas the modern analysis focuses on the still nature of things (Chia, 1995). From the view of postmodernists there is no best way existing to solve a specific problem. Moreover, since the management is determined by the nature of changing environment, one management approach doesn't necessarily generate the same result in all organizations so there is no best management approach (Miller and Tsang, 2011). Additionally, the management practices are influenced by the national institution structures and culture diversity (Zheng and Hyland, 2007). Nevertheless, the trend of globalization, advanced technology and market integration may also contribute to the homogeneity in management worldwide (Tregaskis and Brewster, 2006). Dowling et al. (1999) claimed that this convergence makes the universal principles of the best HRM practices across countries and cultures possible. And according to the study of Carr and Pudelko (2006) MNCs imitate 'the best HRM practices' worldwide commonly in practices. It is evident that the forces of globalization standardized some elements of the management systems (Hall and Soskice, 2001).

\section{Contingency Theory}

Contingency theory claims that there is no best approach for management and leadership. Management and leadership should be based on the internal and external circumstances. The main point of the theory is to design the structure of organization and leadership to adapt to the internal and external changes (Burns and Stalker, 1961). In terms of leadership, Fiedler (1986) proposed a model containing the relationship between leadership style and the favorableness of the situation. Leaders of different traits fit in different situations. Three dimensions of the model are leader-member relationship, degree of task structure and the leader's position.

The implications of contingency theory for the internationalized world consist of the influences on organizations and the leadership. As for organizations, there is no best way to organize the firm since it is heavily contingent on the environment and context of the Multinational company (MNC) (Forsgren 2008). The study of Banalieva and Sarathy (2011) shows that the internationalization-performance relationship is not the same in all emerging market MNCs. Moreover, the survey results of Torre et al. (2011) indicate that the contingency view exists well in MNCs on regional level but not obvious on global level. In terms of leadership, based on Fiedler's contingency theory, Triandis (1993) first claimed that a cultural contingency leadership model should adjust to the culture dimensions.

Nevertheless, there are drawbacks of Fiedler's contingency theory about leadership. The leadership theory failed to take into account other aspects of the leader (e.g., experience) which influence the effectiveness of leadership. And scholars are not sure whether the measurement of leadership style in this theory (Least Preferred Co-worker Scale) can really measure the styles of leaders accurately (Ashour, 1973). 


\section{Behavioral Management Theory}

While the contingency theory focuses on the relationship between management and environment, the behavioral management theory takes a closer look at the people in the organizations. Behavior management consists of all actions and conscious inactions to promote people's probability, personally or in the groups, to choose the behaviors that are fulfilling, productive, and acceptable socially (Baldwin and Baldwinn, 1986). Maslow's hierarchy of human needs (1943) is foundational to behavioral management. McGregor (1960) described the attitudes of employees as two categories: negative at work (Theory $\mathrm{X}$ ) and positive at work (Theory $\mathrm{Y}$ ).

Behavioral management theory still links to the current management theories and practices. In the internationalized world, MNCs are experiencing problems about managing diversity on gender, culture, ages, religions, etc. Diversity management, which is an emerging field, help the organization tackle the oppression on race, culture, gender and other diversities of the individuals to facilitate the healthy development of the organizations. Behavioral management theory is the theoretical foundation of this new field since diversity management utilizes behavioral science methodology to deal with diversity problems (Brazzel, 2003). Based on the behavioral theories, training, counseling and coaching projects for the development and change of the individual, for boosting motivation of employees and for leadership have been built to meet the demands of diversity management (Brazzel, 2003).

The practical evidences of diversity and behavioral management are obvious. One piece of evidence is the international training and development (ITD) program for managers in the organizations of global environment (Ronny, 2007). Managers in the globalised company experience culture problems and misunderstanding. The well-designed ITD program provides a series of training such as culture-awareness training and global mindset training to help the managers adapt to different culture contexts and cooperate well with people from different countries thus motivating the managers to be more successful and improving the performance of the organization. One evidence is SAP's global team building about communication, trust, responsibility and sharing (Global Integration, 2013), which is based on understanding behaviors of employees from diverse background and aimed at promoting the global team performance, showed the implications of the behavioral management theory and diversity management.

But as for Maslow's hierarchy of needs, the order in the five needs is not arguable (Hofstede, 1984). The importance of each need in the hierarchy varies among different countries, among different ages and among different periods of time (Tang, Ibrahim and West, 2002). This limitation will undermine the effectiveness of motivating employees from different background as the managers cannot figure out what the real needs of each individual.

\section{Systems Theory}

Unlike behavioral management theory which mainly focuses on the individuals in the organizations, systems theory considers the whole organizations and the external environment. The general systems model includes inputs, processes and outputs and was first illustrated by Boulding (1956). Systems theory has influence the management and the study of organizations significantly. Johnson et al. (1964) illustrated the application of systems theory in business and proposed a model clarifying the planning, control and communications in the organization. Systems thinking, which is based on systems theory, is the base of the learning organization in Senge's the Fifth Discipline (1990).

Systems theory is closely related to the globalised world. Firstly, systems theory is one of the theoretical roots in diversity management. In diversity management, the effective interaction among individuals of different background is essential. To conduct diversity management with a systematical approach, the National Training Laboratories (NTL) Institute for Applied Behavioral Science offers T-group programs that provide learning on interrelationship among people, self-awareness, and the growth and innovations of organizations (Brazzel, 2003). Secondly, 
systems theory exists in the global outsourcing approach of the strategic management in enterprises. Since organizations are socio-technical systems, they function openly to the outer societal and political environment. Nowadays, a large number of companies interact with other companies to optimize the business performance (Thoppil and Machado, 2010). Thirdly, the concept of learning organization impacts the management in MNCs, although some scholars doubt the realization of the practices of Senge's learning organization (Caldwell, 2012). Exploring the learning process among expatriates and the local employees in Russian MNCs, Engelhard and Nagele (2003) found that organizational learning based on system thinking help analyze the learning barriers of cross-cultural learning and claimed that organizational learning should be closely combined with cross-cultural management after time.

\section{Conclusion}

In conclusion, these classical theories of organization management: taylorism, contingency theory, behavioral management theory and systems theory, develop to link to the burning issues in the globalised world and contribute to the management of organizations theoretically and practically. Taylorism's four principles have connections with measurement of knowledge production, total quality management, empowerment of employees and teamwork management. Previous mechanical taylorism is transforming to the digital taylorism transcending national borders. Contingency theory responds to the 'one-best-way' limitation of taylorism. The theory helps illustrate the relationship between internationalization and the performance in MNCs and is foundational to the cultural contingency leadership model. Behavioral management theory responds to the lack of considering human needs in taylorism and is one of the basic theories for diversity management, international training and development programs in order to motivate individuals and promote performance. Finally, systems thinking, which views the organization as an organism rather than mechanism of taylorism, is a foundation of diversity management, global outsourcing approach of enterprises and learning organizations. Although there are limitations for each theory, it is possible that one can compensate another and there will be more advanced organizational theories responding to these classical theories in the future to make the framework of organization management clearer thereby contributing to the organizational development in the globalization era.

\section{References}

[1] Ashour, A. S. (1973) The Contingency Model of Leadership Effectiveness: An Evaluation. Organizational Behavior and Human Decision Processes, 9(3), 339-55.

[2] Baldwin J.D. and Baldwinn J.I. (1986). Behavior principles in everyday life, 2nd Ed. Engle Wood Cliffs, New Jersey: Prentice Hall.

[3] Banalieva, E. R. and Sarathy. R (2011) A Contingency Theory of Internationalization. Management International Review, 51, 593-634.

[4] Boulding, K. (1956) General Systems Theory - The Skeleton of the Science. Management Science, 2(3), 197-208.

[5] Brazzel, M. (2003) Historical and theoretical roots of diversity management IN: Plummer, D. L. (ed.) Handbook of Diversity Management: Beyond Awareness to Competency Based Learning. Lanham, MD: University Press of America, 51-93.

[6] Brown, P., Ashton, D. and Lauder, H. (2010) Skills are not enough: the globalization of knowledge and the future UK economy. Praxis, 4(3), 1-33.

[7] Burns, T. and Stalker, G. M. (1961) The Management of Innovation. London: Tavistock.

[8] Caldwell, R. (2012) Leadership and Learning: A Critical Reexamination of Senge's Learning Organization. Journal of Change Management, 12(2), 145-164.

[9] Carr, C. and Pudelko, M. (2006) Convergence of management practices in strategy, finance and HRM between the USA, Japan and Germany. International Journal of Cross Cultural Management, 6(1), 75-99. 